\title{
Soil Temperature Prior to Veraison Alters Grapevine Carbon Partitioning, Xylem Sap Hormones, and Fruit Set
}

\author{
Stewart K. Field, ${ }^{1,2 *}$ Jason P. Smith, ${ }^{1}$ Erin N. Morrison, ${ }^{3}$ \\ R.J. Neil Emery, ${ }^{3}$ and Bruno P. Holzapfel ${ }^{1,4}$
}

\begin{abstract}
To gain a better understanding of environmental effects on grapevines and the physiological regulation of acclimation, we determined the effects of soil temperature $\left(14\right.$ or $\left.24^{\circ} \mathrm{C}\right)$ between anthesis and veraison on growth, nonstructural carbohydrates, cytokinins, abscisic acid, and leaf function of potted Vitis vinifera cv. Shiraz. Plants of each regime were selected from two groups that had been grown in a glasshouse from three weeks prior to budbreak at an average soil temperature of either 13 or $23^{\circ} \mathrm{C}$. Soil temperature between anthesis and veraison affected utilization and restoration of root and trunk nonstructural carbohydrates and changes in biomass of major plant organs. Soil warming promoted shoot growth via utilization of starch reserves, while soil cooling promoted starch storage in both the root and wood and shifted overall biomass partitioning to the roots. A change in soil temperature from warm to cool through flowering was also associated with reduced fruit set. Diurnal courses of photosynthesis, transpiration, and stomatal conductance after fruit set were significantly affected by soil temperature. Phytohormones (cytokinin and abscisic acid) were measured in the xylem sap and leaves at fruit set and veraison. Differences between these two sample types during grapevine development highlight a phytohormone shift likely involved in postveraison fruit ripening. We conclude that soil temperature significantly affects grapevine growth and that the responses are mediated largely by an influence of temperature on mobilization of nonstructural carbohydrates from the roots.
\end{abstract}

Key words: abscisic acid, cytokinin, nonstructural carbohydrate, root temperature, trans-zeatin, xylem sap

Temperature is a key environmental factor that influences grapevine phenology, growth, and berry development. Air temperature has been primarily used to define climatic suitability for vineyard site location. However, temperature will have increasing importance on management decisions and varietal selection as the climate of existing grape producing regions is expected to warm through the coming decades (Jones et al. 2005). The effects of soil temperature on grapevine growth and physiology are of practical interest because of the potential to modify root-zone temperatures independently of air temperature. Soil temperatures can be manipulated in

\footnotetext{
${ }^{1}$ National Wine and Grape Industry Centre, Charles Sturt University, Locked Bag 588, Wagga Wagga, New South Wales, Australia 2678; ${ }^{2}$ Current address: Viticulture and Wine Department, Nelson Marlborough Institute of Technology, 85 Budge Street, Blenheim 7240, New Zealand; ${ }^{3}$ Biology Department, Trent University, Peterborough, ON K9J 7B8, Canada; and ${ }^{4}$ New South Wales Department of Primary Industries, Wagga Wagga, Australia.

*Corresponding author (stewart.field@nmit.ac.nz)

Acknowledgments: This work was supported by Australia's grapegrowers and winemakers through their investment body the Grape and Wine Research and Development Corporation, with matching funds from the Australian Government, and by the Commonwealth Cooperative Research Centres Program. The work was conducted by the NWGIC, Charles Sturt University, within the Cooperative Research Centre for Viticulture program. The authors thank Robert Lamont for technical support.
}

Manuscript submitted May 2019, revised Sept 2019, accepted Oct 2019

Copyright $(2020$ by the American Society for Enology and Viticulture. All rights reserved.

By downloading and/or receiving this article, you agree to the Disclaimer of Warranties and Liability. The full statement of the Disclaimers is available at http://www.ajevonline.org/content/proprietary-rights-notice-ajev-online. If you do not agree to the Disclaimers, do not download and/or accept this article. doi: 10.5344/ajev.2019.19038 the short-to-medium term through mulching with organic material or plastic sheeting (Van Der Westhuizen 1980) or may vary in response to cultivation or cover cropping practices (Pradel and Pieri 2000). In an experimental trial intended to maximize the soil temperature differential between treatments, differences of up to $8^{\circ} \mathrm{C}$ (at depths of 10 and $30 \mathrm{~cm}$ ) were achieved between heavy straw mulching and plastic applied under the vine row (Holzapfel et al. 2016). In the establishment of vineyards, row orientation, row spacing, and trellis design provide opportunities for longer-term modification of soil temperatures by varying the shading of solar radiation to the vineyard floor. A better understanding of the effect of root-zone temperature on grapevine physiology may therefore improve the management of vineyards in a warming climate.

Earlier studies of root-zone temperature effects on grapevine growth and development have largely relied on the use of potted plants in controlled environments. These studies have ranged from 11 to $30^{\circ} \mathrm{C}$ and either covered shorter periods from three to eight weeks after budbreak (Woodham and Alexander 1966, Skene and Kerridge 1967) or a longer period from dormancy to harvest (Zelleke and Kliewer 1979). The general finding across these experiments was that the highest biomass production and shoot growth rates were observed with the warmest treatment regimes. These studies did not use root-zone temperature treatments above $35^{\circ} \mathrm{C}$, which is the temperature that may affect root survival (Huang et al. 2005). However, observations made by Woodham and Alexander (1966) suggest that shoot growth can be restricted or stopped if the differential between soil and air temperature is too great. Grapevine responses to soil temperature may therefore vary according to the environmental conditions experienced by the aboveground parts of the plant. 
Previously, we have shown that soil temperature between dormancy and anthesis greatly affects the rate of carbohydrate reserve utilization for re-establishment of the canopy (Field et al. 2009). This suggested a direct effect of soil temperature on the mobilization of reserve carbohydrates in the root. The subsequent period from anthesis to veraison (i.e., E-L stages 23 and 35, respectively [Pearce and Coombe 2005]), is particularly important from a commercial perspective because fruit set and the initial stages of berry development contribute to yield every season.

The importance of phytohormones, particularly cytokinins (CKs), have been examined in relation to their role in crop yield and influence on plant cell division and differentiation (Mok and Mok 2001) and maintenance of source-sink strength through the mobilization of nutrients. Biotic and abiotic factors can greatly affect CK concentrations within plants (Mauch-Mani and Mauch 2005). Soil temperature was found to influence the concentration of specific CKs in the xylem sap of Shiraz grapes (Field et al. 2009). For example, increased levels of dihydrozeatin riboside (DHZR) and transzeatin riboside (transZR) were detected in the xylem sap of grapevines grown in warmer soil temperatures, and it was suggested that this may stimulate shoot development in grapevines (Field et al. 2009). The dominance of CK types can vary among plant species as well as the location in the plant (Schäfer et al. 2015). Isopentenyl (iP) CKs have been found to accumulate during fruit ripening in the berries of Shiraz and other grapevine cultivars, likely due to tissue specific CK production (Böttcher et al. 2015). Cytokinins can also be transported throughout the plant with trans-zeatin (transZ)type CKs found mainly in the xylem sap (root-to-shoot transport), whereas iP types are mainly found in the phloem or leaf exudates. This suggests that transZ CKs are important in root-to-shoot signaling and iP are mainly transported from source to sink organs (Matsumoto-Kitano et al. 2008).

The phytohormone abscisic acid (ABA) plays a role in seed maturation and dormancy, regulation of stomatal aperture, as well as plant stress response and adaptation to environmental changes (Mauch-Mani and Mauch 2005, Bakht et al. 2013). ABA levels have been found to increase and aid in cold tolerance of some species (Bakht et al. 2013). Understanding the role of ABA with soil temperature, as well as the potential interaction between phytohormone groups, is important.

In this study, we show that soil temperature between anthesis and veraison has a strong influence on grapevine growth and biomass distribution and that a change in soil temperature prior to anthesis has a marked interactive effect on these responses-including the seasonal restoration of root carbohydrate reserves and the percentage of fruit set. These responses are interpreted in terms of carbohydrate reserve dynamics and their effect on photoassimilation and water use. Associated fluxes in xylem CKs and ABA, some of which have been shown to respond to soil temperature early in the season (Field et al. 2009), are examined to further elucidate their role in mediating grapevine responses to the soil environment.

\section{Materials and Methods}

Experimental system and plant material. From dormancy to anthesis, own-rooted three-yr-old vines, cv. Shiraz, were grown in a glasshouse in $26-\mathrm{L}(60 \mathrm{~cm}$ high) insulated pots with soil maintained at an average temperature of either 13 or $23^{\circ} \mathrm{C}$ with a cooled or heated recirculating water system (Figure 1; Field et al. 2009). At anthesis, two additional treatments were added by changing the soil temperature of half the vines in each treatment to the other soil temperature
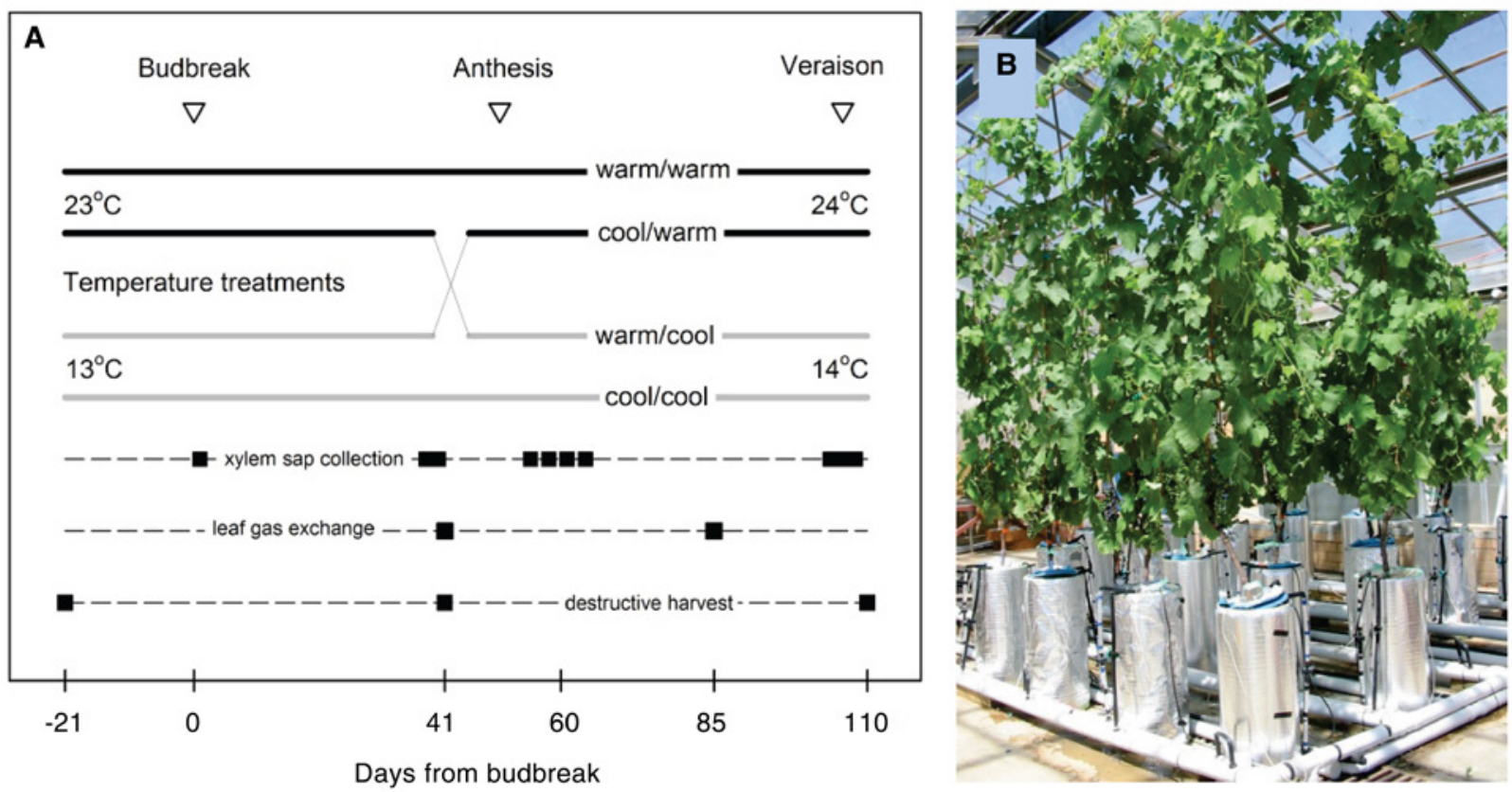

Figure 1 Schematic diagram of root-zone temperature treatment schedule in relation to developmental stage and measurement schedule (A), and the root-zone temperature control system and remaining vines just prior to the final destructive harvest at veraison (B). 
treatment (i.e., half of the vines that were previously grown at a cool soil temperature of $13^{\circ} \mathrm{C}$ prior to flowering were switched to the warm soil temperature of $23^{\circ} \mathrm{C}$ ) (Figure 1). From this point on, the treatments are referred in the text as cool $/$ cool $\left(13^{\circ} \mathrm{C}\right.$ budbreak to anthesis $/ 13^{\circ} \mathrm{C}$ anthesis to veraison), cool/warm $\left(13^{\circ} \mathrm{C} / 23^{\circ} \mathrm{C}\right)$, warm/warm $\left(23^{\circ} \mathrm{C} / 23^{\circ} \mathrm{C}\right)$ and warm $/$ cool $\left(23^{\circ} \mathrm{C} / 13^{\circ} \mathrm{C}\right)$, respectively.

Soil temperature was recorded at $5 \mathrm{~min}$ intervals, at a depth of $20 \mathrm{~cm}$ in the center of each pot, using an automated logging system connected to digital temperature sensors (Maxim Integrated Products). Soil temperatures did not differ by more than $0.5^{\circ} \mathrm{C}$ between pots. During the period from anthesis to veraison, the average soil temperature was increased by $2^{\circ} \mathrm{C}$ in all treatments to avoid large differences between the increasing air temperature and the $13^{\circ} \mathrm{C}$ tank temperature (Figure 2). Air temperature, which was moderated by evaporative air-conditioning but not specifically controlled, was maintained between mean daily temperatures of 12 to $27^{\circ} \mathrm{C}$ (Figure 2). Light was provided only by natural solar radiation.

All pots were filled with a 4:4:2 mixture of sandy loam, gravel, and peat when plants were initially planted. This allowed for a water-holding capacity of $\sim 4 \mathrm{~L}$ of plant-available water per pot. Plants were watered daily to the point that excess water drained freely from the pots. Throughout the experiment, vines were fertilized monthly with $200 \mathrm{~mL}$ of $20: 1$ diluted complete liquid fertilizer (Megamix plus, Rutec). The vines were sprayed with wettable sulfur and copper sulfate throughout the season to prevent mite and fungus infections.

Measurements. Each vine was trained to three vertical shoots with two inflorescences per shoot when possible. This resulted in five to six inflorescences per vine. Flower and berry number per inflorescence were determined at anthesis and veraison, respectively. The number of flowers was determined by enclosing each inflorescence in a nylon mesh bag just before flower opening and subsequently counting abscised flower caps and unopened flowers. Fruit set was determined

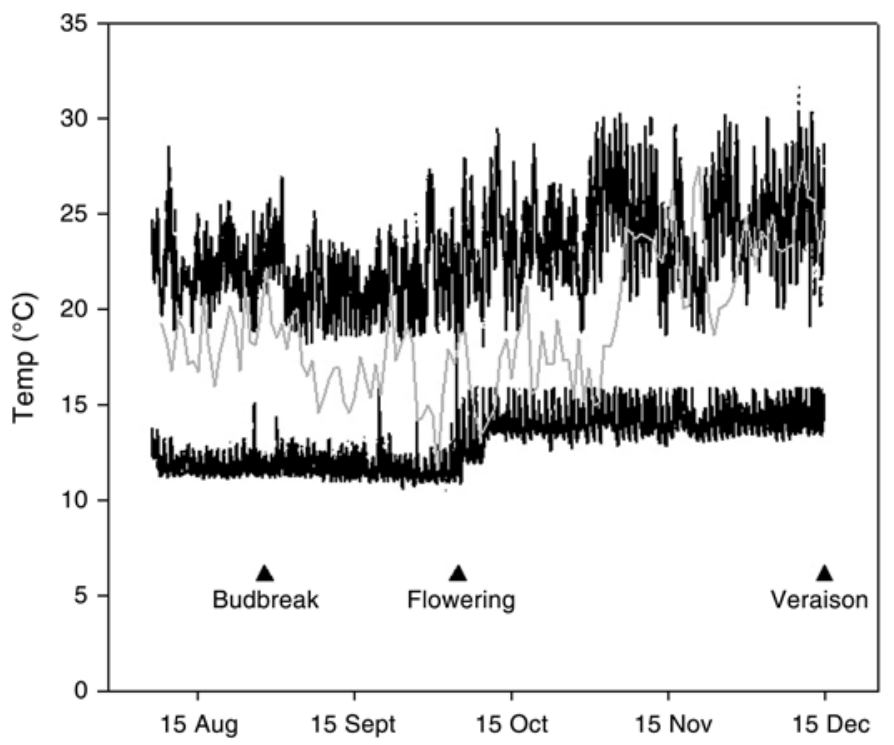

Figure 2 Mean daily air temperature (grey line) and mean temperature of pots at a soil depth of $20 \mathrm{~cm}$ (approximately center of root mass). Temperatures were logged every $5 \mathrm{~min}$ for the duration of the experiment. when abscission of the undeveloped flowers and unexpanded ovaries ceased. Fruit set was quantified as the relationship between the number of berries and number of flowers expressed as a percentage.

At three days prior to the start of cap-fall and at the completion of the study ( $\sim 50 \%$ veraison), five vines per treatment were destructively harvested; separated into root, trunk, shoot, leaf, and fruit components; and washed and oven dried at $70^{\circ} \mathrm{C}$ for dry biomass measurement. Nonstructural carbohydrates (starch, sucrose, D-glucose, and D-fructose) in the roots and trunk were determined by the method described by Field et al. (2009). Total nitrogen concentration was determined by combustion analysis on a $50 \mathrm{mg}$ subsample using a VarioMAX combustion analyzer (Elementar). At veraison, 100-berry samples for each potted vine were randomly collected and squashed, and the homogenized juice was used for determining the total soluble solids (Brix) using a digital refractometer (ATAGO PR-101). The remainder of the 100-berry sample was incorporated into the fruit component for dry weight biomass measurement.

The diurnal pattern of leaf photosynthesis, transpiration, stomatal conductance, and water potential was determined on a clear day (3 Nov) during the season between fruit set and veraison. Leaf photosynthesis, transpiration, and stomatal conductance measurements were made using an LCA4 gas analyzer (ADC Bioscientific), and this was immediately followed by measuring the leaf water potential using a Scholander-type pressure chamber. Each measurement was made on the most recently fully expanded leaf on two shoots of each plant.

Xylem sap collection and phytohormone analysis. Xylem sap was collected from three plants of each treatment through a 10-day period spanning the fruit set period and then again through a five-day period shortly prior to veraison using the root pressure chamber method described by Field et al. (2009). At the time of xylem sap collection, one leaf was excised and immediately frozen at $-80^{\circ} \mathrm{C}$. The xylem sap and leaf concentrations of ABA, transZ, cis-zeatin (cisZ), dihydrozeatin (DHZ), iP, transZR, cis-zeatin riboside (cisZR), DHZR, isopentenyl adenosine (iPA), zeatin $O$-glucoside (ZOG), zeatin riboside $O$-glucoside (ZROG), dihydrozeatin $O$-glucoside (DHZOG), trans-zeatin nucleotide (transZRP), cis-zeatin nucleotide (cisZRP), dihydrozeatin nucleotide (DHZRP), and isopentenyl nucleotide (iPRP) were determined according to the method of Ross et al. (2004) for ABA and Quesnelle and Emery (2007) for CKs.

Statistical analysis. For statistical analysis of reproductive development, growth, biomass components, and nonstructural carbohydrates in the anthesis-veraison period, a $2 \times 2$ factorial design with preconditioning and current soil temperature with five replicates was used (Genstat, Rothhamsted Experimental Station). Within grapevine inflorescences, percentage fruit set varies inversely with flower number per inflorescence (Keller 2015). With differences in flower numbers between treatments observed in our study, linear regression was used to examine the overall relationship between flower numbers and berry numbers, and this was then extended to each treatment to test for differences in slope and intercept. 
Means \pm standard errors are presented for the $\mathrm{CK}$ and $\mathrm{ABA}$ concentrations.

\section{Results}

Shoot growth and leaf number. Soil temperature before anthesis had no effect on the total length of primary shoots, total leaf number, or leaf area. However, soil warming between anthesis and veraison significantly $(p<0.01)$ increased average shoot length relative to the vines growing in cooled soil (Figure 3A). Within the cooled treatment, the reduction in growth was greater for the vines grown in warm soil between budbreak and anthesis. Leaf number per shoot was not significantly different (Figure 3B).

Biomass partitioning, nonstructural carbohydrates, and total $\mathbf{N}$. At veraison, fruit biomass of preanthesis warmed vines was significantly lower (Table 1). However, there was no significant difference in the other total dry biomass components of plants that had been warmed or cooled in both time periods (Table 1). Although, the ratio of shoot-to-root mass was $40 \%$ greater in postanthesis warmed plants. The decrease in the root:shoot ratio under the warm soil regime was caused by an increase in shoot and lateral growth and a decrease in root biomass (Table 1). The decrease in root biomass was associated with significantly lower storage of starch in the roots of warmed vines (19.5 $\mathrm{g}$ DW/vine) compared to the cooled vines (41.1 g DW/vine).

In both roots and trunks, the concentration of starch decreased between dormancy and anthesis (Figure 4). When the
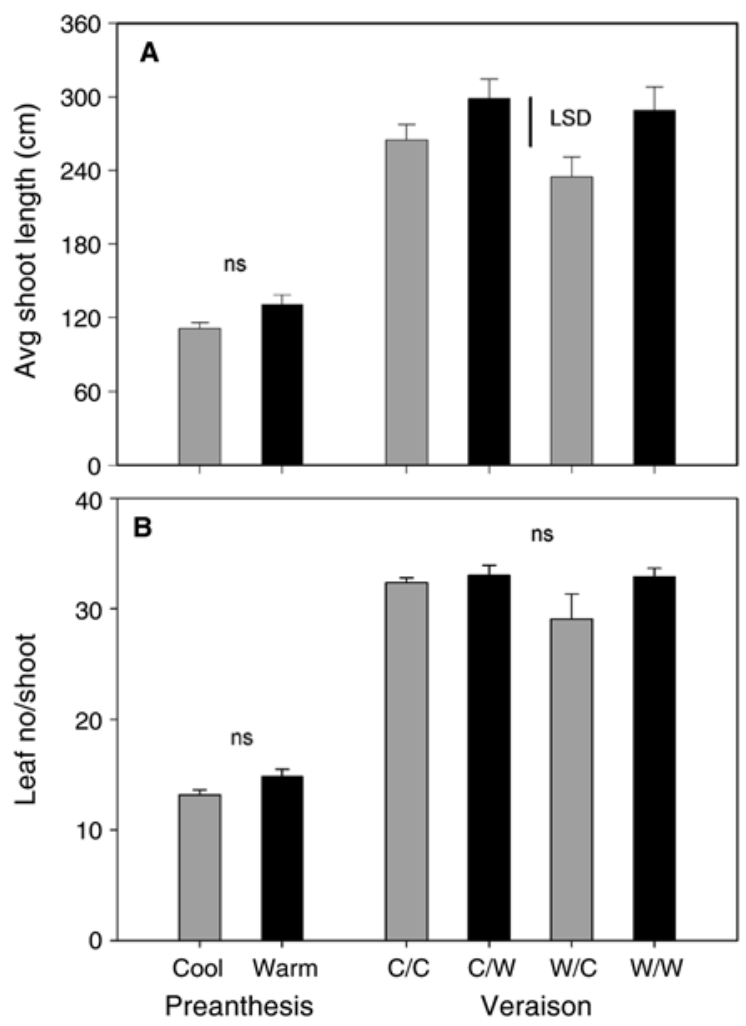

Figure 3 Effect of root-zone temperature on average shoot length $(\mathbf{A})$ and leaf number per shoot $(\mathbf{B})$ as recorded prior to anthesis and at veraison. Least significant difference (LSD) indicates significant difference between treatments at $p \leq 0.05$. ns $=$ not significant. Error bars $\pm \mathrm{SE}$ mean $(\mathrm{n}$ $=15)$. C, cool; W, warm. soil temperatures were switched, the shift from cool to warm caused a decrease in root starch to comparable levels in vines that had been grown continuously in the warm soil. Conversely, a switch from warm to cool resulted in an increase of root starch concentrations to levels similar to that of vines grown continuously in the cool soil (Figure 4A). Trunk starch initially responded to the soil temperature treatments in a similar manner to root starch, with concentrations decreasing more in the warm than cool soil treatment after budbreak. However, the response was less pronounced during the second treatment period, and starch concentrations at veraison mainly reflected the differences established at anthesis (Figure 4B). No statistically significant differences were observed for soluble sugar concentrations in both the wood and root.

Tissue $\mathrm{N}$ concentrations (in percentage dry weight $[\% \mathrm{DW}]$ ) and total content (in grams per vine [g/vine]) were in most cases not responsive to soil temperature treatment. A significant increase was observed $(14 \%)$ in root $\mathrm{N}$ concentration in response to soil warming between budbreak and anthesis. However, this increase in concentration was not associated with an increase in uptake, with no significant difference in root $\mathrm{N}$ content ( $\mathrm{g} / \mathrm{vine}$ ) observed.

Reproductive development. Soil temperature prior to anthesis had no effect on flower number per inflorescence, with an average of 247 flowers per inflorescence in the cool treatment and 273 in the warm treatment. However, there was a significant interaction across the four treatment combinations, but as flower numbers were already established before the four temperature regimes were commenced at anthesis, this was attributed to preexisting variation between vines. For a given number of flowers per inflorescence, the number of berries was reduced significantly by cooling the root zone of previously warmed vines (Table 2). There was no difference between the other three treatments. This reduction was reflected at fruit set, although not significantly, with prewarmed and then cooled vines having lower berry numbers per bunch (Table 2) and reduced fruit weight (Table 1) at veraison. Soil temperature had no significant effect on berry sugar concentrations at the time of veraison (Table 2).

Leaf water potential and gas exchange. Three weeks prior to veraison, the diurnal courses of photoassimilation, transpiration, and stomatal conductance of single, newly matured leaves of plants were significantly different between treatments (Figure 5). Photoassimilation, transpiration, and stomatal conductance of plants grown continuously in the warmed soil were generally higher throughout the day than those of plants grown continuously in the cooler soil. By midmorning, the leaf water potentials of the plants in cool soil were lower than those in the warm soil, despite their lower stomatal conductance and leaf area, but the difference had diminished by midday, at which time the leaf water potential of both warmed and cooled plants was about -1.2 MPa (Figure 5).

CKs and ABA. CK ribosides were the main CKs detected in xylem sap at fruit set, with the predominant CK detected across all treatments being transZR (Table 3). Within the precursor nucleotide fraction, DHZRP was the predominant $\mathrm{CK}$ detected, and trans $\mathrm{Z}$ was the dominant $\mathrm{CK}$ in the freebase 
fraction. Trans-cytokinin (trans $\mathrm{CK}$ ) types were present in all treatment types, whereas cis-cytokinin (cis CK) types (with the exception of cisZRP) and $O$-glucosides were not detected within the xylem sap at fruit set (Table 3). In the corresponding leaf samples, all $15 \mathrm{CKs}$ analyzed were detected with a greater contribution from the nucleotide forms. The most abundant CKs detected were DHZR and ZROG, followed by iPRP and transZRP. CisCK types and $O$-glucosides were detected in all leaf tissue sampled, highlighting the difference in CK profiles between xylem sap and leaves at fruit set.

At veraison, the type of CKs identified in the xylem sap was similar to that observed at fruit set (Table 4), with DHZ$\mathrm{RP}$ remaining the dominant form in the nucleotide fraction. The main difference between the two dates was the concentration of transZ and transZR, which decreased by a factor of 10 and eight, respectively, between fruit set and veraison. In addition, transZ was no longer detected in cool/warm and warm/cool treatments. For the leaf samples at veraison, the CK profile was similar to the leaves collected at fruit set. The most notable difference in terms of contribution to the overall leaf CK pool was an increase in the average concentration of iPRP from 82 to $289 \mathrm{pmol} \mathrm{g} / \mathrm{DW}$. However, DHZR and ZROG remained among the more abundant CKs detected.

At veraison, the xylem sap concentrations of transZR, DHZR, and iPA in postanthesis-warmed plants were lower than the cooled vines. For all xylem sap and leaf samples collected at fruit set and the leaf samples from veraison, there was no apparent effect of soil temperature treatment on the type or concentration of CKs.

No differences in ABA concentrations were observed in the xylem sap at fruit set (Table 3). However, veraison xylem sap ABA concentrations in continuously warmed vines were higher than in continuously cooled vines (Table 4). Interestingly, veraison xylem sap ABA concentrations in vines that had been switched at anthesis were between the two extremes of the continuously treated plants.

\section{Discussion}

Biomass partitioning and nonstructural carbohydrates. Altering soil temperature from budbreak was previously

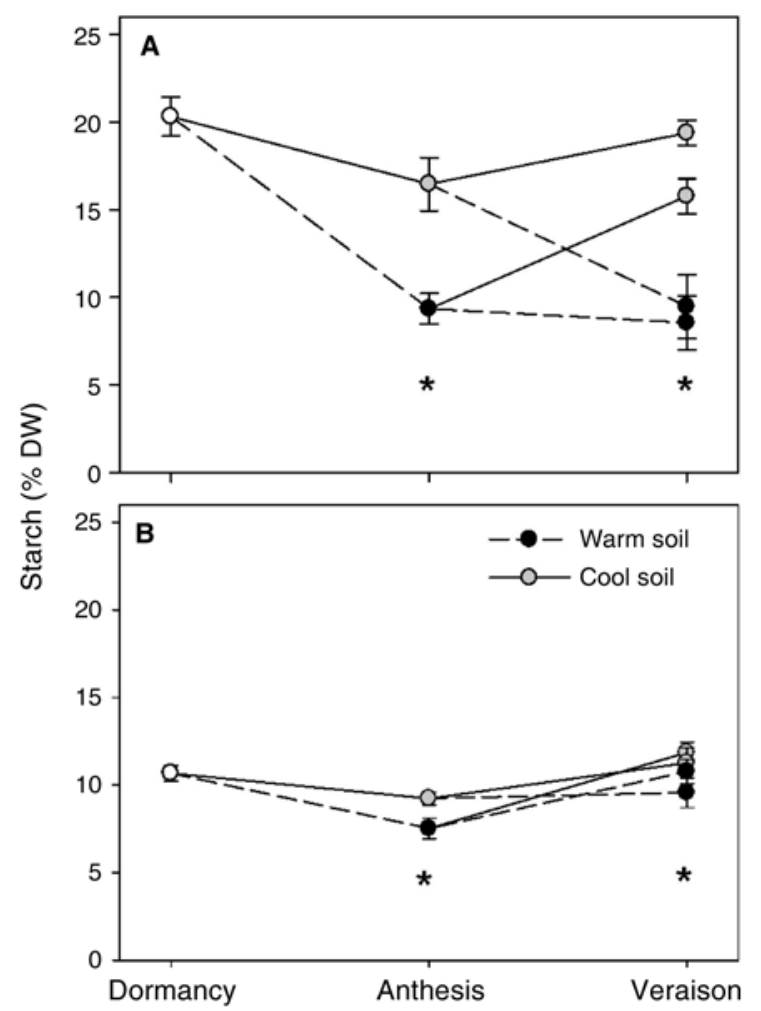

Figure 4 Effect of root-zone temperature on starch concentrations in root (A) and trunk (B) tissue from dormancy to veraison. ${ }^{*}$ indicates significant difference between treatments at $p \leq 0.05$. Error bars \pm SE mean $(n=5)$. DW, dry weight.

Table 1 Biomass components and root:shoot ratio of potted Shiraz grapevines at veraison as influenced by root-zone temperature treatments between budbreak and veraison. DW, dry weight.

\begin{tabular}{|c|c|c|c|c|c|c|c|c|}
\hline \multirow[b]{2}{*}{ Treatment } & \multicolumn{2}{|c|}{$\begin{array}{c}\text { Shoot } \\
\text { (g DW) }\end{array}$} & \multicolumn{5}{|c|}{$\begin{array}{c}\text { Total biomass } \\
\text { (g DW) }\end{array}$} & \multirow{2}{*}{$\begin{array}{c}\text { Root:shoot } \\
\text { ratio }\end{array}$} \\
\hline & Main & Lateral & Root & Trunk & Shoot & Fruit & Vine & \\
\hline \multicolumn{9}{|l|}{ Budbreak-anthesis } \\
\hline Cool & 169 & 29.0 & 220 & 120 & 198 & 46.7 & 585 & 1.1 \\
\hline Warm & 156 & 21.5 & 224 & 124 & 177 & 37.0 & 562 & 1.3 \\
\hline \multicolumn{9}{|l|}{ Anthesis-veraison } \\
\hline Cool & 150 & 20.1 & 233 & 121 & 170 & 39.3 & 564 & 1.4 \\
\hline Warm & 174 & 30.4 & 211 & 123 & 205 & 44.3 & 583 & 1.0 \\
\hline \multicolumn{9}{|l|}{ Temperature regime } \\
\hline Cool/cool & 160 & 24.0 & 231 & 119 & 184 & 45.9 & 580 & 1.3 \\
\hline Cool/warm & 177 & 33.9 & 209 & 122 & 211 & 47.4 & 590 & 1.0 \\
\hline Warm/cool & 140 & 16.2 & 235 & 124 & 156 & 32.8 & 548 & 1.5 \\
\hline Warm/warm & 172 & 26.8 & 213 & 123 & 198 & 41.3 & 576 & 1.1 \\
\hline \multicolumn{9}{|l|}{ Significance } \\
\hline Budbreak-anthesis & $n s^{a}$ & ns & ns & ns & ns & * & ns & ns \\
\hline Anthesis-veraison & ns & * & ns & ns & ns & ns & ns & ** \\
\hline Interaction & ns & ns & ns & ns & ns & ns & ns & ns \\
\hline
\end{tabular}

${ }^{a *},{ }^{* *}$, and $n s$ indicate significance at $p \leq 0.05, p \leq 0.01$, and not significant, respectively. 
shown to have little effect on the total dry biomass of grapevines at anthesis, but temperature differences caused dry biomass to be partitioned differently (Field et al. 2009). Soil warming between budbreak and anthesis promoted shoot biomass accumulation and leaf area development at the expense of root starch reserves (Field et al. 2009, Rogiers et al. 2011). Conversely, when a cooler soil temperature regime was maintained across the same period, shoot biomass was reduced, but the rate of mobilization or utilization of root starch was also decreased. The effects of soil temperature regime in the period between anthesis and veraison were consistent with these vine responses. That is, there was no overall difference in whole vine biomass, but a significantly lower root:shoot ratio with warmer soil. Soil warming caused a decline in root starch concentrations of previously cooled vines, while starch concentrations of the continuously warmed plants remained low. Under cooled soil conditions, all vines had significantly higher starch in the roots at veraison. This was particularly pronounced for the previously warmed vines, which more than doubled the amount of stored starch from anthesis to veraison. These results illustrate that soil temperature can exert considerable influence on the balance between starch accumulation (storage) and utilization (annual growth). The enhanced aboveground growth of grapevines in sites where the soil warms rapidly in spring has been noted previously, particularly in cool sites (Jackson 2001). It is now clear that this response is attributable to accelerated utilization of carbohydrate reserves.

Another interesting finding was that fruit biomass at the time of veraison was significantly higher in vines that had

Table 2 Effect of root-zone temperature treatments between budbreak and veraison on reproductive development parameters of potted Shiraz grapevines.

\begin{tabular}{|c|c|c|c|c|c|}
\hline Treatment & $\begin{array}{c}\text { Flowers/ } \\
\text { inflorescence }\end{array}$ & $\begin{array}{c}\text { Berries/ } \\
\text { cluster }\end{array}$ & $\begin{array}{c}\begin{array}{c}\text { Fruit set } \\
(\%)\end{array} \\
\end{array}$ & $\begin{array}{c}\text { Berry/flower no. } \\
\text { relationship }\end{array}$ & $\begin{array}{c}\text { Soluble solids } \\
\text { (Brix) }\end{array}$ \\
\hline $\mathrm{Cool} / \mathrm{cool}$ & $230 a^{a}$ & 85 & $38.7 \mathrm{~b}$ & $y=0.17 x+44.8 b$ & 7.1 \\
\hline Cool/warm & 269 a & 88 & $34.2 \mathrm{~b}$ & $y=0.17 x+41.4 b$ & 6.8 \\
\hline Warm/cool & $304 \mathrm{~b}$ & 76 & $26.1 \mathrm{a}$ & $y=0.17 x+23.6 a$ & 7.2 \\
\hline Warm/warm & $240 a$ & 81 & $35.3 \mathrm{~b}$ & $y=0.17 x+39.5 b$ & 6.3 \\
\hline Significance & $* \mathrm{~b}$ & ns & * & * & ns \\
\hline
\end{tabular}

Within columns, means followed by different letters are significantly different.

${ }^{b *}$ and ns indicate significance at $p \leq 0.05$, and not significant, respectively.
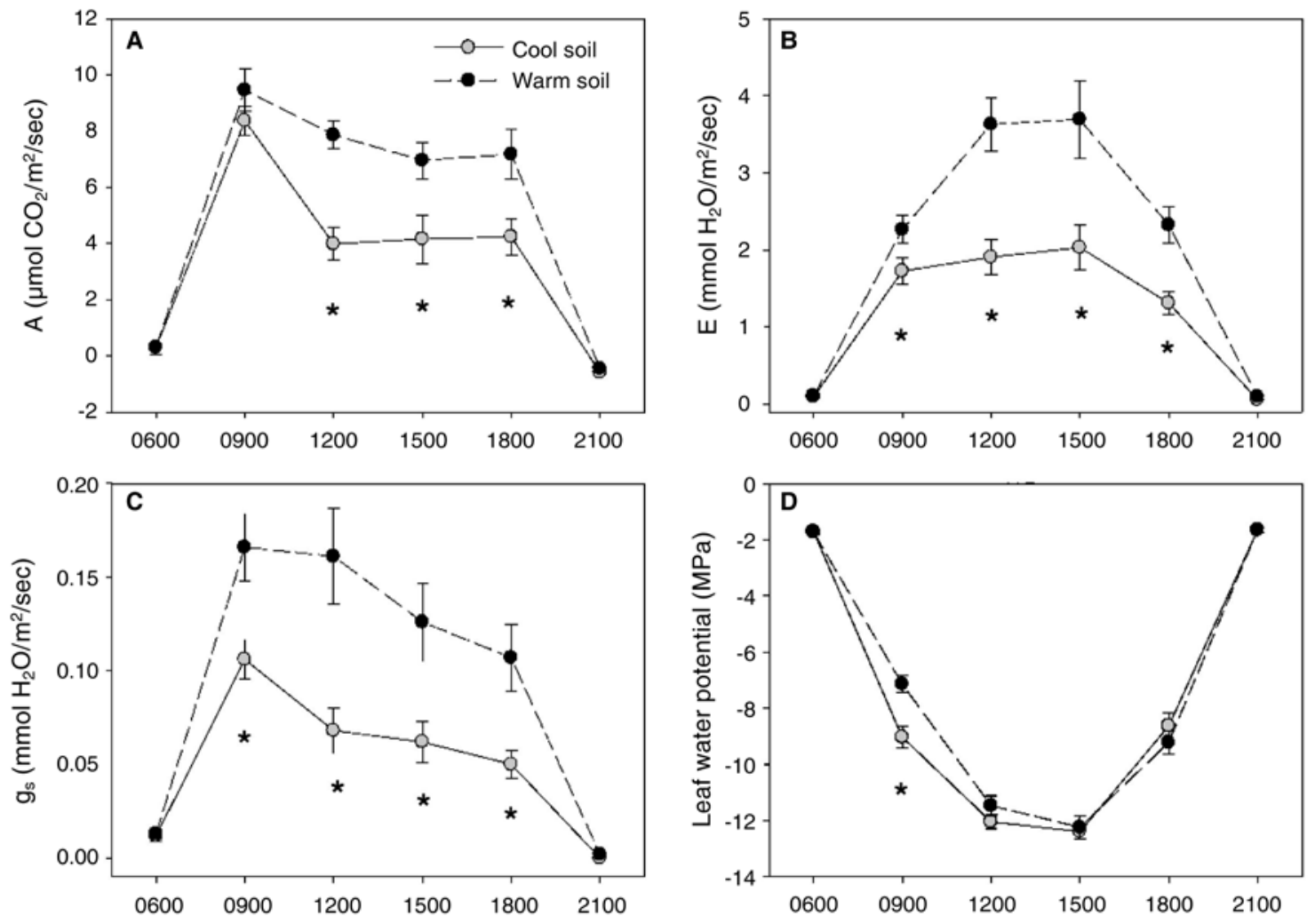

Time of day (hr)

Figure 5 Effect of root-zone temperature in the anthesis-veraison period on leaf diurnal photosynthesis (A), transpiration (B), stomatal conductance (C), and leaf water potential (D) as measured 85 days after budbreak (three weeks prior to veraison). * indicates significant difference between treatments at $p \leq 0.05$. Error bars \pm SE mean $(n=10)$. 
previously been cooled prior to anthesis. This is possibly attributed to these plants having significantly greater root reserves at anthesis to support early berry growth. Many studies have reported that mobilization of carbohydrate reserves are used to help negate the effects of reduced assimilation (i.e., through leaf defoliation) on fruit development (see review by Holzapfel et al. 2010).

Flowering and fruit set. In grapevines, the transition from flower to berry relies on photoassimilates, normally from basal leaves (Keller 2015). Concurrent demand for those assimilates from growing shoots and restoration of carbohydrate reserves limit their availability for fruit set, as inferred from treatments that enhance fruit set, such as trunk girdling or shoot tipping, or those that diminish it, e.g., severe pruning, defoliation, or leaf shading (see review by Holzapfel et al. 2010). Our study revealed that soil temperature-induced tensions in carbohydrate demand during flowering influence the degree of fruit set. Lower fruit-set percentage was induced by cooling previously warmed roots. Tabing et al. (2013) also found that reducing the root temperature from 20 to $10^{\circ} \mathrm{C}$ for a two-week period over flowering reduced fruit set in cv. Chardonnay vines. Interestingly, in this study, the marked reduction in fruit set was associated with the increase in root carbohydrates. Poor fruit set has been attributed to competition with rapid shoot growth (May 2004). However, after removing potential effects of different flower numbers at anthesis (by regression analysis), plants with the lowest shoot growth rate (elongation or dry biomass) between anthesis and veraison had significantly less fruit set than all other treatments. This is attributable to the fact that restoration of root carbohydrate reserves was also occurring during this period to a greater extent ( $200 \%$ greater) than all other treatments. This demonstrates a strong acclimation that favors reserve accumulation over maximal fruit set, at least when demand by both functions is simultaneous. It also suggests that viticultural practices such as shoot tipping and application of growth retardants to improve fruit set are not likely to be effective when root carbohydrate reserves are low and restoration is favored by cool soil temperature.

Fruit set remained unaffected when the cool soil temperature was maintained postanthesis. This can be largely attributed to their higher reserve status at the onset of flowering. Continuously warmed plants also had unimpaired fruit set. Accelerated foliar development, including a high proportion of fully autotrophic proximal leaves possibly accounted for this. Rogiers et al. (2014) also showed that constant soil temperature up until fruit set (warm, ambient, or cool) had no effect on the percentage of fruit set. Cool/warm-treated vines, with greater mobilization of reserves to the shoot during flowering to veraison, interestingly had no effect on fruit set. Biomass analysis suggests these reserves were utilized solely in shoot growth.

Poor fruit set is sometimes attributed to restricted nutrient uptake from cold soil. However, no significant differences in

Table 3 Effect of root-zone temperature treatments between budbreak and fruit set on concentration of cytokinins and abscisic acid (ABA) identified in xylem sap and leaves of Shiraz grapevines at the time of fruit set. DW, dry weight.

\begin{tabular}{|c|c|c|c|c|c|c|c|c|}
\hline \multirow[b]{2}{*}{ Cytokinin $^{a}$} & \multicolumn{4}{|c|}{ Fruit set xylem sap (pmol/mL) } & \multicolumn{4}{|c|}{ Fruit set leaf (pmol/g DW) } \\
\hline & Cool/cool & Cool/warm & Warm/cool & Warm/warm & Cool/cool & Cool/warm & Warm/cool & Warm/warm \\
\hline \multicolumn{9}{|l|}{ Free base } \\
\hline transZ & $0.8 \pm 0.2^{b}$ & $1.2 \pm 0.1$ & $1.2 \pm 0.4$ & $0.9 \pm 0.3$ & $7.5 \pm 3.3$ & $7.5 \pm 3.3$ & $4.0 \pm 1.5$ & $5.4 \pm 0.8$ \\
\hline $\operatorname{cisZ}$ & nd & nd & nd & nd & $9.3 \pm 3.7$ & $10.7 \pm 3.6$ & $17.3 \pm 4.3$ & $17.1 \pm 2.0$ \\
\hline $\mathrm{DHZ}$ & $d$ & nd & nd & nd & $2.1 \pm 0.5$ & $1.7 \pm 0.6$ & $1.9 \pm 0.5$ & $2.0 \pm 0.2$ \\
\hline iP & $d$ & $0.1 \pm 0.0$ & $0.1 \pm 0.0$ & $d$ & $1.8 \pm 0.0$ & $2.8 \pm 0.6$ & $2.7 \pm 0.3$ & $2.5 \pm 0.3$ \\
\hline \multicolumn{9}{|l|}{ Riboside } \\
\hline transZR & $10.2 \pm 5.1$ & $10.1 \pm 2.0$ & $10.7 \pm 4.0$ & $10.0 \pm 3.1$ & $5.9 \pm 0.5$ & $6.3 \pm 0.2$ & $5.0 \pm 1.0$ & $9.5 \pm 1.7$ \\
\hline cisZR & nd & nd & nd & nd & $1.1 \pm 0.2$ & $0.7 \pm 0.0$ & $1.0 \pm 0.1$ & $1.3 \pm 0.1$ \\
\hline DHZR & $0.9 \pm 0.3$ & $0.9 \pm 0.1$ & $0.9 \pm 0.2$ & $0.8 \pm 0.2$ & $98.6 \pm 17.3$ & $87.2 \pm 43.1$ & $83.6 \pm 19.5$ & $83.1 \pm 13.7$ \\
\hline iPA & $0.9 \pm 0.3$ & $0.7 \pm 0.1$ & $1.1 \pm 0.3$ & $1.1 \pm 0.3$ & $8.4 \pm 0.3$ & $10.1 \pm 1.1$ & $11.8 \pm 0.6$ & $16.3 \pm 6.6$ \\
\hline \multicolumn{9}{|c|}{ O-glucosides } \\
\hline ZROG & nd & nd & nd & nd & $93.5 \pm 23.8$ & $62.2 \pm 16.7$ & $67.4 \pm 8.3$ & $56.3 \pm 14.2$ \\
\hline DHZOG & nd & nd & nd & nd & $3.9 \pm 0.6$ & $5.1 \pm 1.0$ & $4.3 \pm 0.7$ & $4.1 \pm 1.1$ \\
\hline ZOG & nd & nd & nd & nd & $7.0 \pm 1.0$ & $4.1 \pm 0.7$ & $5.3 \pm 0.6$ & $5.8 \pm 1.3$ \\
\hline \multicolumn{9}{|l|}{ Nucleotides } \\
\hline transZRP & $0.9 \pm 0.2$ & $1.4 \pm 0.5$ & $1.3 \pm 0.6$ & $1.5 \pm 0.2$ & $71.8 \pm 12.0$ & $73.2 \pm 2.0$ & $72.8 \pm 21.5$ & $147.4 \pm 26.4$ \\
\hline cisZRP & $0.1 \pm 0.1$ & $0.1 \pm 0.1$ & $0.2 \pm 0.1$ & $0.1 \pm 0.1$ & $12.3 \pm 2.3$ & $9.2 \pm 3.5$ & $12.7 \pm 3.6$ & $15.6 \pm 0.8$ \\
\hline DHZRP & $1.2 \pm 0.2$ & $1.2 \pm 0.0$ & $1.2 \pm 0.1$ & $1.0 \pm 0.0$ & $14.6 \pm 2.8$ & $34.4 \pm 0.3$ & $19.1 \pm 5.2$ & $30.4 \pm 3.6$ \\
\hline iPRP & $0.2 \pm 0.2$ & $0.1 \pm 0.0$ & $0.1 \pm 0.0$ & $0.1 \pm 0.0$ & $61.0 \pm 13.9$ & $90.6 \pm 24.0$ & $93.4 \pm 11.1$ & $82.8 \pm 21.4$ \\
\hline ABA & $149 \pm 9$ & $137 \pm 25$ & $211 \pm 41$ & $120 \pm 12$ & & & & \\
\hline
\end{tabular}

atransZ, trans zeatin; cisZ, cis-zeatin; $\mathrm{DHZ}$, dihydrozeatin; $\mathrm{P}$, isopentenyl adenine; transZR, trans-zeatin riboside; cisZR, cis-zeatin riboside; $\mathrm{DHZR}$, dihydrozeatin riboside; iPA, isopentenyl adenosine; ZROG, zeatin riboside O-glucoside; DHZOG, dihydrozeatin O-glucoside; ZOG, zeatin O-glucoside; transZRP, trans-zeatin nucleotide; cisZRP, cis-zeatin nucleotide; DHZRP, dihydrozeatin nucleotide; iPRP, isopentenyl nucleotide. ${ }^{b}$ Means \pm SE mean $(n=3)$; $n d=$ not detected; $d$ = below limit of quantification $(<0.05 \mathrm{pmol} / \mathrm{mL})$. 
$\mathrm{N}$ content ( $\mathrm{g} / \mathrm{vine})$ between treatments and the normal fruit set in the continuously cooled plants indicate that nutrient uptake was not a factor in this regard. Furthermore, improved nutrient uptake seen in vines grown in a warmer soil had no effect on the percentage of fruit set in a similar experimental setup (Rogiers et al. 2014, Clarke et al. 2015).

CKs and ABA. transZR was the major CK form in the xylem sap at the times of flowering and fruit set and is consistent with the CK profile of xylem sap in many other plants (Emery and Atkins 2002). However, nucleotide forms that were not detected at flowering (Field et al. 2009) were apparent both at fruit set and veraison, when DHZRP was one of the main dominant CK forms along with transZR. Thus, marked changes in the xylem sap CK profile occurred across the season. Notably, at the time of veraison, transZR concentrations were considerably higher in vines subjected to cool soil temperature postanthesis.

Soil temperature treatment had little or no effect on stomatal conductance, photoassimilation rate, or transpiration of the most recently fully expanded leaves at anthesis (Field et al. 2009). However, by the completion of fruit set 40 days later, leaf gas exchange measurements of similar aged leaves were significantly lower in vines grown in cooler soil. It is well known that low soil temperatures decrease transpiration by reducing absorption of water directly by decreasing the permeability and hydraulic conductivity of roots to water and indirectly by increasing the viscosity of water (Kozlowski
1987). Those effects may have contributed to both the lower transpiration rate and the lower midmorning leaf water potential of the cooled plants. As leaf area increased markedly between the time of flowering and veraison in the present study for vines in all treatments, the total canopy transpiration would have increased concomitantly. If low root conductance had occurred in cooled vines, then supply of water to the vines would have been impeded in this treatment. Leaf transpiration rates in cooled vines were indeed significantly reduced compared to vines in warmer soil, which is consistent with a restricted supply of water. Reductions in stomatal conductance apparently mediated the low transpiration rates of the cooled vines to maintain the vine water potential.

ABA has been shown in numerous studies to reduce transpiration by closing stomata in response to water stress (Keller 2015). However, our study did not convey this with warmed vines, with assumed higher stomatal conductance, having higher ABA concentrations in the xylem sap at veraison. Veselova et al. (2005) found that differences in stomatal opening caused by different root temperatures were not caused by ABA. Furthermore, their work revealed that decreased levels of $\mathrm{CK}$ in the xylem sap closed stomata of wheat seedlings when roots were cooled. CKs are known to be involved in regulating stomatal conductance, with application of synthetic CK generally opening the stomata and reversing the effect of ABA on stomata under water stress (Stoll et al. 2000). However, application of benzylaminopurine (BAP) at low concentrations to

Table 4 Effect of root-zone temperature treatments between budbreak and veraison on concentration of cytokinins and abscisic acid (ABA) identified in xylem sap and leaves of Shiraz grapevines at the time of veraison. DW, dry weight.

\begin{tabular}{|c|c|c|c|c|c|c|c|c|}
\hline \multirow[b]{2}{*}{ Cytokinin $^{a}$} & \multicolumn{4}{|c|}{ Veraison xylem sap (pmol/mL) } & \multicolumn{4}{|c|}{ Veraison leaf (pmol/g DW) } \\
\hline & Cool/cool & Cool/warm & Warm/cool & Warm/warm & Cool/cool & Cool/warm & Warm/cool & Warm/warm \\
\hline \multicolumn{9}{|l|}{ Free base } \\
\hline transZ & $0.3 \pm 0.3^{b}$ & nd & nd & $0.1 \pm 0.06$ & $3.5 \pm 0.5$ & $3.1 \pm 0.4$ & $7.8 \pm 3.2$ & $9.9 \pm 3.2$ \\
\hline $\operatorname{cisZ}$ & nd & nd & nd & $0.1 \pm 0.05$ & $25.0 \pm 5.1$ & $13.1 \pm 2.5$ & $13.8 \pm 7.1$ & $22.2 \pm 8.9$ \\
\hline $\mathrm{DHZ}$ & nd & nd & nd & nd & $2.5 \pm 0.7$ & $2.4 \pm 0.8$ & $4.1 \pm 0.9$ & $3.1 \pm 1.2$ \\
\hline iP & $0.1 \pm 0.0$ & $d$ & $d$ & $0.1 \pm 0.01$ & $5.0 \pm 0.6$ & $3.3 \pm 0.6$ & $6.8 \pm 2.1$ & $5.7 \pm 0.5$ \\
\hline \multicolumn{9}{|l|}{ Riboside } \\
\hline transZR & $3.0 \pm 1.6$ & $0.2 \pm 0.1$ & $2.0 \pm 0.8$ & $0.2 \pm 0.08$ & $6.4 \pm 0.2$ & $5.1 \pm 1.3$ & $12.4 \pm 2.7$ & $11.0 \pm 4.9$ \\
\hline cisZR & nd & nd & $d$ & nd & $0.8 \pm 0.0$ & $0.9 \pm 0.0$ & $0.9 \pm 0.2$ & $1.1 \pm 0.3$ \\
\hline DHZR & $0.6 \pm 0.1$ & $0.3 \pm 0.0$ & $0.5 \pm 0.1$ & $0.2 \pm 0.01$ & $47.2 \pm 6.6$ & $87.1 \pm 9.5$ & $68.8 \pm 5.9$ & $57.0 \pm 9.0$ \\
\hline iPA & $0.3 \pm 0.0$ & $d$ & $0.3 \pm 0.1$ & $0.1 \pm 0.03$ & $37.7 \pm 23.4$ & $14.6 \pm 4.6$ & $29.6 \pm 5.8$ & $19.2 \pm 4.0$ \\
\hline \multicolumn{9}{|c|}{ O-glucosides } \\
\hline ZROG & nd & nd & nd & nd & $67.1 \pm 8.4$ & $74.0 \pm 21.8$ & $97.6 \pm 20.2$ & $94.1 \pm 15.2$ \\
\hline DHZOG & nd & nd & nd & nd & $6.4 \pm 0.5$ & $6.9 \pm 0.8$ & $6.2 \pm 1.2$ & $8.1 \pm 1.1$ \\
\hline ZOG & nd & nd & nd & nd & $11.8 \pm 2.1$ & $18.6 \pm 7.3$ & $22.1 \pm 7.6$ & $17.1 \pm 0.6$ \\
\hline \multicolumn{9}{|l|}{ Nucleotides } \\
\hline transZRP & $0.7 \pm 0.3$ & $0.2 \pm 0.0$ & $0.6 \pm 0.1$ & $0.4 \pm 0.06$ & $78.0 \pm 26.9$ & $65.5 \pm 16.4$ & $126.7 \pm 19.5$ & $81.2 \pm 19.4$ \\
\hline cisZRP & $0.1 \pm 0.1$ & nd & nd & $0.1 \pm 0.07$ & $11.4 \pm 2.1$ & $16.9 \pm 1.6$ & $19.5 \pm 7.3$ & $12.5 \pm 2.4$ \\
\hline DHZRP & $2.5 \pm 1.4$ & $1.1 \pm 0.1$ & $0.7 \pm 0.0$ & $1.3 \pm 0.10$ & $14.6 \pm 2.0$ & $10.6 \pm 1.1$ & $15.0 \pm 1.2$ & $14.4 \pm 4.9$ \\
\hline iPRP & $0.1 \pm 0.0$ & $0.1 \pm 0.0$ & $0.1 \pm 0.0$ & $0.1 \pm 0.01$ & $263.8 \pm 35.0$ & $194.7 \pm 40.5$ & $442.4 \pm 82.7$ & $254.2 \pm 54.0$ \\
\hline ABA & $116 \pm 16$ & $142 \pm 24$ & $151 \pm 10$ & $206 \pm 8$ & & & & \\
\hline
\end{tabular}

atransZ, trans zeatin; cisZ, cis-zeatin; DHZ, dihydrozeatin; iP, isopentenyl adenine; transZR, trans-zeatin riboside; cisZR, cis-zeatin riboside; DHZR, dihydrozeatin riboside; iPA, isopentenyl adenosine; ZROG, zeatin riboside O-glucoside; DHZOG, dihydrozeatin O-glucoside; ZOG, zeatin O-glucoside; transZRP, trans-zeatin nucleotide; cisZRP, cis-zeatin nucleotide; DHZRP, dihydrozeatin nucleotide; iPRP, isopentenyl nucleotide. ${ }^{b}$ Means \pm SE mean $(n=3)$; $n d=$ not detected; $d=$ below limit of quantification $(<0.05 \mathrm{pmol} / \mathrm{mL})$. 
leaves of sugar maple (Reeves et al. 2007) reduced stomatal conductance by up to $40 \%$. Furthermore, when ZR and iPA were introduced into the transpiration stream of well watered Arubutus unedo plants, there was no stimulatory effect on transpiration, with ZR even reducing transpiration compared to control plants (Burschka 1985, as cited in Fußeder et al. 1992). Therefore, the higher concentrations of riboside CKs in the xylem sap of vines exposed to cool soil conditions at veraison relative to those exposed to warm conditions could possibly be a root-to-shoot signal that closed the stomata in response to low temperature-induced reductions in root hydroconductivity.

Leaf CK concentrations did not differ greatly nor was there a consistent pattern between the soil treatments. However, the $\mathrm{CK}$ profile in leaf tissue differed from the xylem sap, with DHZR, ZROG, transZRP, and iPRP being the predominant $\mathrm{CK}$ forms at both sample times. These differences in CK profiles between xylem sap and leaf tissue highlight the different and changing roles of CKs from fruit set to veraison. The dominance of transZ CK types, particularly transZR relative to iP types in the xylem sap, highlight the biased distribution of these CKs within the plant. Root-derived transZ CKs are typically found in the xylem, and Ip-type CKs are typically found in the phloem (Hirose et al. 2008). This compartmentalization of CKs suggests selective transport systems for trans $\mathrm{Z}$ and iP types and their role in acropetal and systemic long distance signals (Hirose et al. 2008). Grafting experiments using multiple isopentenyltransferase (a key gene in CK biosynthesis) Arabidopsis thaliana mutants highlighted the importance of root-derived transZ CKs and their transport from root to shoot being necessary in shoot development (Matsumoto-Kitano et al. 2008). In the current study, no cisZ $\mathrm{CKs}$ or $\mathrm{O}$-glucosides were detected in the xylem sap, further supporting the role of CK compartmentalization and dominance of CK transport in the xylem and not CK processing or local synthesis during this time. At veraison, xylem sap transZR was reduced relative to fruit set; this may reflect a switch from $\mathrm{CK}$ long distance signaling from root-shoot $\mathrm{CKs}$ in the xylem toward a preference for local CK production in the leaves and fruit. This switch in CK dominance would reflect the developmental changes that occur postveraison, i.e., fruit ripening. Böttcher et al. (2015) noted a decreased contribution of trans $\mathrm{Z} \mathrm{CKs}$ and an increased concentration of iP in grape berries during fruit ripening in four grapevine cultivars. Böttcher et al. (2015) also identified 38 CK-related genes and examined their expression across 16 weeks postflowering in developing Shiraz grape berries. Developmental changes in the expression of genes related to CK biosynthesis, processing, etc., suggested that local CK biosynthesis more likely contributes to the postveraison accumulation of iP within the examined grapevine berries (Böttcher et al. 2015).

Long distance transport as well as local $\mathrm{CK}$ production in the Shiraz grapevine leaves during fruit set and veraison is reflected in the abundance of $\mathrm{CK}$ forms detected. Nucleotide $\mathrm{CKs}$ are precursors to active CKs and are considered the first product in CK biosynthesis; these are modified to semiactive ribosides that are further modified to the active freebase forms
(Sakakibara 2006). This sequence of CK processing can be modified through direct activation of nucleotide forms to freebases (further explanation Frébort et al. 2011). The detection of higher levels of nucleotides, particularly iPRP (at veraison) in the leaves indicate local $\mathrm{CK}$ production may become more important during this development change, as well as reflect the potential shift from transZ to iP CK type dominance.

The shifts in CK concentration within xylem sap as well as leaf tissue may reflect the changing role of xylem-derived root $\mathrm{CKs}$ toward local CK production. Thus, xylem sap CK involved in the mobilization of starch-derived solutes early in the season may possibly change roles to regulating leaf stomatal conductance later in the season when leaves are able to supply their CK needs.

Viticultural implications. The effect of soil temperature and its seasonal consequences has previously received little attention compared with atmospheric temperature. Although soil temperature and atmospheric temperature correlate generally, grapevine root temperature is also influenced by vineyard soil features such as texture, color, and moisture content (Jackson 2001), and it may be modified greatly by viticultural floor management practices such as mulching interrow swards and cultivation (Walpole et al. 1993) and also by grapevine density and foliar management. Thus, the grapevine growth responses to soil temperature between anthesis and veraison have important practical implications, not only in terms of fruit set and consequent berry development, but also in canopy management and the capacity of grapevines to deal with seasonal contingencies.

\section{Conclusion}

We conclude that soil temperature from dormancy to veraison significantly affects the utilization and restoration of nonstructural carbohydrates from roots and trunks and relative changes in biomass of major plant organs during that period. Enhanced mobilization of starch, from warming previously cooled roots, appears to support increased shoot and leaf growth. Carbohydrate reserve status is shown to condition the magnitude of growth responses to soil temperature between anthesis and veraison. Notably, the responses to warm soil conditions reveal an inherent preference in grapevines under those conditions for shoot and fruit development over carbohydrate reserve accumulation. However, in cool soil, carbohydrate reserve-depleted plants favor recovery over fruiting, at least up to veraison when seed becomes viable and fruit ripening commences. Consequently, soil temperature will alter the level of carbohydrate reserves with which grapevines enter the postveraison phase, hence determining plant capacity to respond to seasonal carbon-related contingencies during fruit ripening and the restorative demand by leaf fall.

An apparent shift from transZ to iP CK type dominating in the leaf tissue later in the season suggests a shift towards local leaf production for supplying CK. Root-derived xylem sap CK, which appears to be important for mobilization of starch early in the season, may possibly change roles to regulating leaf stomatal conductance later in the season. 
Finally, in view of the effects of soil temperature on grapevines ranging from seasonal balances between shoot and root growth, floral development, plant water use, photosynthesis, and the temporal availability of carbohydrate reserves, we conclude that soil temperature and the influence of cultural practices warrant much closer attention in viticultural systems.

\section{Literature Cited}

Bakht J, Bano A, Shafi M and Dominy P. 2013. Effect of abscisic acid applications on cold tolerance in chickpea (Cicer arietinum L.). Eur J Agron 44:10-21.

Böttcher C, Burbidge CA, Boss PK and Davies C. 2015. Changes in transcription of cytokinin metabolism and signalling genes in grape (Vitis vinifera L.) berries are associated with the ripening-related increase in isopentenyladenine. BMC Plant Biol 15:223.

Burschka C. 1985. Der Einfuß von Abscisinsäure auf die stomatäre Regulation des Wasserhaushaltes bei der immergrünen Mediterranpflanze Arbutus unedo unter natürlichen Bedingungen. PhD dissertation, Universität Würzburg, FRG.

Clarke SJ, Lamont KJ, Pan HY, Barry LA, Hall A and Rogiers SY. 2015. Spring root-zone temperature regulates root growth, nutrient uptake and shoot growth dynamics in grapevines. Aust J Grape Wine Res 21:479-489.

Emery RJN and Atkins CA. 2002. Cytokinins and roots. In Plant Roots: The Hidden Half. Waisel Y et al. (eds.). pp. 417-434. Marcel Dekker Inc., N.Y.

Field SK, Smith JP, Holzapfel BP, Hardie WJ and Emery RJN. 2009. Grapevine response to soil temperature: Xylem cytokinins and carbohydrate reserve mobilization from budbreak to anthesis. Am J Enol Vitic 60:164-172.

Frébort I, Kowalska M, Hluska T, Frébortová J and Galuszka P. 2011. Evolution of cytokinin biosynthesis and degradation. J Exp Bot 62:2431-2452.

Fußeder A, Wartinger A, Hartung W, Schulze E-D and Heilmeier H. 1992. Cytokinins in the xylem sap of desert-grown almond (Prunus dulcis) trees: Daily courses and their possible interactions with abscisic acid and leaf conductance. New Phytol 122:45-52.

Hirose N, Takei L, Kuroha T, Kamada-Nobusada T, Hayashi H and Sakakibara H. 2008. Regulation of cytokinin biosynthesis, compartmentalization and translocation. J Exp Bot 59:75-83.

Holzapfel BP, Smith JP, Field SK and Hardie WJ. 2010. Dynamics of carbohydrate reserves in cultivated grapevines. In Horticultural Reviews. Vol. 37. Janick J (ed), pp. 143-211. John Wiley and Sons, New Jersey.

Holzapfel BP, Smith JP, Greer DH, Dunn G and Hardie J. 2016. Effects of modifying root temperature in field grown 'Cabernet Sauvignon' on carbohydrate reserve dynamics and vine development. Acta Hortic 1115:87-94.

Huang X, Lakso AN and Eissenstat DM. 2005. Interactive effects of soil temperature and moisture on Concord grape root respiration. $\mathrm{J}$ Exp Bot 56:2651-2660.

Jackson D. 2001. Climate: Monographs in Cool Climate Viticulture-2. Daphne Brasell Associates, Wellington, NZ.

Jones GV, White MA, Cooper OR and Storchmann K. 2005. Climate change and global wine quality. Clim Change 73:319-343.

Keller M. 2015. The Science of Grapevines: Anatomy and Physiology. 2nd ed. Elsevier/Academic Press, Amsterdam.

Kozlowski TT. 1987. Soil moisture and absorption of water by tree roots. J Arboricult 13:39-46.

Matsumoto-Kitano M, Kusumoto T, Tarkowski P, Kinoshita-Tsujimura K, Vaclavikova K, Miyawaki K and Kakimoto T. 2008. Cytokinins are central regulators of cambial activity. P Natl Acad Sci USA 105:20027-20031.
Mauch-Mani B and Mauch F. 2005. The role of abscisic acid in plantpathogen interactions. Curr Opin Plant Biol 8:409-414.

May P. 2004. Flowering and Fruitset in Grapevines. Lythrum Press, Adelaide.

Mok DWS and Mok MC. 2001. Cytokinin metabolism and action. Annu Rev Plant Physiol Plant Mol Biol 52:89-118.

Pearce I and Coombe BG. 2005. Grapevine phenology. In Viticulture. Vol. 1. Resources. 2nd ed. Dry PR and Coombe BG (eds.), pp.150166. Winetitles, Adelaide.

Pradel E and Pieri P. 2000. Influence of a grass layer on vineyard soil temperature. Aust J Grape Wine Res 6:59-67.

Quesnelle PE and Emery RJN. 2007. cis-Cytokinins that predominate in Pisum sativum during early embryogenesis will accelerate embryo growth in vitro. Can J Bot 85:91-103.

Reeves I, Farrow SC and Emery RJN. 2007. Patterns of cytokinins and leaf gas exchange among canopy layers of a mature sugar maple (Acer saccharum) stand. Trees-Struct Funct 21:181-189.

Rogiers SY, Smith JP, Holzapfel BP and Hardie WJ. 2011. Soil temperature moderates grapevine carbohydrate reserves after budbreak and conditions fruit set responses to photoassimilatory stress. Funct Plant Biol 38:899-909.

Rogiers SY, Clarke SJ and Schmidtke LM. 2014. Elevated root-zone temperature hastens vegetative and reproductive development in Shiraz grapevines. Aust J Grape Wine Res 20:123-133.

Ross ARS, Ambrose SJ, Cutler AJ, Feurtado JA, Kermode AR, Nelson K, Zhou R and Abrams SR. 2004. Determination of endogenous and supplied deuterated abscisic acid in plant tissues by high-performance liquid chromatography-electrospray ionization tandem mass spectrometry with multiple reaction monitoring. Anal Biochem 329:324-333.

Sakakibara H. 2006. Cytokinins: Activity, biosynthesis, and translocation. Ann Rev Plant Biol 57:431-449.

Schäfer M, Brütting C, Meza-Canales ID, Großkinsky DK, Vankova R, Baldwin IT and Meldau S. 2015. The role of cis-zeatin-type cytokinins in plant growth regulation and mediating responses to environmental interactions. J Exp Bot 66:4873-4884.

Skene KGM and Kerridge GH. 1967. Effect of root temperature on cytokinin activity in root exudate of Vitis vinifera L. Plant Physiol 42:1131-1139.

Stoll M, Loveys B and Dry PR. 2000. Hormonal changes induced by partial rootzone drying of irrigated grapevine. J Exp Bot 51:1627-1634.

Tabing O, Tisdal JM and Swain S. 2013. Low temperature exposure of root system and inflorescence affected flowering and fruit set in 'Chardonnay' grapevines (Vitis vinifera). Vitis 52:165-169.

Van Der Westhuizen JH. 1980. The effect of black plastic mulch on growth, production and root development of Chenin blanc vines under dryland conditions. S Afr J Enol Vitic 1:1-6.

Veselova SV, Farhutdinov RG, Veselov SY, Kudoyarova GR, Veselov DS and Hartung W. 2005. The effect of root cooling on hormone content, leaf conductance and root hydraulic conductivity of durum wheat seedlings (Triticum durum L.). J Plant Physiol 162:21-26

Walpole MD, Whiting JR and Code GR. 1993. An evaluation of mulches as substitutes for herbicides during vineyard establishment. In Proceedings of the Eighth Australian Wine Industry Technical Conference. Stockley CS et al. (eds), pp. 100-104. Winetitles, Adelaide.

Woodham RC and Alexander DM. 1966. The effect of root temperature on development of small fruiting Sultana vines. Vitis 5:345-350.

Zelleke A and Kliewer WM. 1979. Influence of root temperature and rootstock on budbreak, shoot growth, and fruit composition of Cabernet Sauvignon grapevines grown under controlled conditions. Am J Enol Vitic 30:312-317. 